\title{
CARACTERÍSTICAS ESPECÍFICAS DO EXAME FÍSICO REALIZADO PELO ENFERMEIRO
}

\author{
Maria Teresa Cícero Laganá* \\ Maria Romana Friedlander** \\ Cibele Andrucioli M. Pimenta* \\ Maria Júlia P. da Silva* \\ Rose Meire Imanich***
}

FRIEDLANDER, M.R. et al. Características específicas do exame fisico realizado pelo enfermeiro. Rev.Esc. Enf. USP, v. 27, n. 1, p. 95-99, abr. 1993.

Trata do exame físico feito pelo enfermeiro, identificando quatro pressupostos básicos oriundos da execução deste procedimento e sugere eixos norteadores indicativos de especificidade para o exame fisico de enfermagem.

UNITERMOS: Exame fisico de cnfermagem. Exc rcício da enfermagem.

\section{I - INTRODUÇĀO}

Quando tentamos especificar a prática do enfermeiro, muitas discussōes acerca das limitações que a definem nos remetem à própria história da enfermagem c de suas teorias mais aceitas, que têm tentado responder à questão da especificidade. Ao relacionarmos especificidade ao exame físico do enfermeiro, está implícita, portanto, a discussão sobre os tênues limites da tão almejada especificidade profissional.

Tentamos então, fazer o delineamento do que cntendemos ser o Exame Físico Específico do Enfermeiro, a partir de pressupostos básicos oriundos da observação da prática do enfermeiro e do docente, bem como da própria estrutura prestadora de assistência à saúde, tal qual a temos concebido por décadas, centrada no modelo alopático. Em seguida sugerimos eixos norteadores para a prática e a pesquisa em enfermagem, em busca da necessária especificidade profissional, benéfica para o enfermeiro e de valor inestimável para a sociedade.

\section{II - PRESSUPOSTOS BÁsicos}

1. O exame físico realizado pelo enfermeiro não apresenta "especificidade".

A maioria das enfermeiras accita como Exame Físico de Enfermagem o processo pelo qual o profissional observa o seu cliente, utilizando os métodos

* Assistente do Departamento de Enfermagem Médico-Cirúrgica da EEUSP.

* * Associado do Departamento de Enfermagem Médico-Cirúrgica da EEUSP.

*** Auxiliar de Ensino do Departamen 
de palpação, inspeç̧āo, percussāo c ausculta, com a linalidade de colher dados de ordem física (anátomo-fisiológicos) para subsidiar os cuidados de enfermagem.

Sem uma estrutura sólida criada pela própria profïssão e tentando resgatar novamente esta atividade, cstamos emprestando os conhecimentos já adquiridos por outro profissional. O médico, profissional de longa tradição, construiu, experimentou e renovou testes e sinais que comprovadamente nos transmitem certas informaçōes.

Este empréstimo de conhecimento, se é válido para desencadear a construção do nosso "saber", levanta a questão da especificidade da enfermagem. A especificidade operacional de uma atividade é definida pela identificação das caractcrísticas que lhe dão um caráter próprio c que não permitcm a confusão cntre essa atividade c outras que sc lhe asscmelham.

Grande parte da assistência de cnfermagem é calcada no modelo médicoalopata, tendo a fisiopatologia como estrutura conceitual e a cura da doença como foco de ação. Assim, neste referencial, o exame físico realizado pclo enfermeiro é scmelhante ao do médico, visto que a base teórica cos objetivos sāo os mesmos.

Embora não se desconheça que o enfermeiro privilegie um ou outro tipo de dado diferentemente do médico, isto nāo chega a atribuir especificidade ao exame físico de enfermagem. Falta um raciocínio consistente para cste "privilegiar um ou outro dado" que seria explicado por um foco de ação claramente definido. Scria desejável e possível um cxame físico com uma perspectiva específica do profissional enfermeiro? Se tivermos fenômenos próprios da enfermagem a atender $c$ uma base conceitual diferente da medicina será necessário, ainda, especificar e desenvolver um novo modelo de levantamento de dados.

2. Existem "demandas de cuidado" que orientam determinados "focos"de atenção do enfermeiro no exame físico.

As demandas de cuidado se traduzem pelos cuidados requeridos pelos pacientcs/clientes para manter a vida, promover saúde $\mathrm{e}$ desenvolver o bem estar individual. Conforme a qualidade de vida quer proporcionar aos indivíduos, "a enfermagem procura satisfazer os requerimentos de cuidados somáticos, psíquicos e culturais, num primeiro nível; requerimentos de suporte (familiar, de grupos de pertencimento e coletivo) num scgundo nível c, num terceiro nível, os requerimentos de cuidados universais, que seriam destinados aos clientes capazes de se cuidarem de modo independente do profissional, dentro dos limites do autocuidado". ${ }^{3}$

Os focos de atenção do enfermeiro, orientados, então, pelas diferentes demandas de cuidado de enfermagem, determinam múltiplas orientações para 
a realização do exame físico, que acabam por não ter uma base teórica própria que o sustente.

Embora a proposta de a tendimento holístico seja predominante no cuidado ao paciente/cliente, os focos de atenção do enfermeiro no exame físico são extremamente móveis c oscilam conforme os fenômenos de enfermagem que se quer atender. No entanto, estes fenômenos não estão claramente delimitados e nem há consenso sobre qua is sejam os fenômenos cm enfermagem: Seriam os desequilíbrios tendo como referencial a teoria das Necessidades Humanas Básicas? As evidências de sinais e sintomas indicativas de intervenção de enfermagem? As capacidades para o autocuidado e as habilidades para a manutenção das atividades da vida diária relacionadas com saúde e doença dos pacientes/clientes?

$\mathrm{Na}$ enfermagem $\mathrm{cm}$ neurociência ${ }^{4}$, por exemplo, identificou-se seis fenômenos específicos para a área: consciência, cognição, comunicação, sensação, sexualidade, mobilidade, sono e repouso. Sobre estes fenômenos têm-se tentado desenvolver e especificar o levantamento de dados, onde o exame físico teria características peculiares que definiriam o foco de atenção do enfermeiro.

Na área de Saúde da Mulher ${ }^{1}$, por outro lado, tem-se encontrado um grau de resolutividade significante a partir da concepção do foco próprio da enfermagem como o auto-cuidado, aplicando-se na prática, os conceitos de Educação para o Auto-cuidado e avaliando-se os resultados obtidos. Neste caso, a orientação do Exame Físico está circunscrita na necessidade de colher informaçōes úteis à realização de programas de Educação para a Saúde.

Como se vê, os fenômenos a serem privilegiados e o foco que se quer dar às açōes, direcionam o tipo de dado a ser levantado.

No entanto, o foco de ação deveria ter uma base de conhecimento teórico relacionado aos fenômenos da profissão. Na maioria das vezes o fazer do profissional parece estar centrado na fisiopatologia, mas, também, percebe-se aspectos calcados nas ciências humanas (psicologia, sociologia e ciências do comportamento) e na concepção de auto-cuidado, notando-se a mobilidade na base teórica da enfermagem.

3. O instrumento de coleta de dados para o exame físico geralmente é impróprio ou insuficiente para determinar condutas de enfermagem .

A base teórica inespecífica do exame físico do enfermeiro restringe a coleta de dados, confundindo o tipo de dados a ser levantado. Assim, se o foco de ação é pouco claro e a base teórica bastante variável não há possibilidade de um levantamento de dados com características próprias, específicas do profissional. 


\section{A autonomia técnica do enfermeiro traduz-se por decisões de cuidado}

geralmente $n$ ão invasivas.

O primeiro fator que deveria auxiliar a prática do enfermeiro ao examinar o cliente relaciona-se à utilidade dos dados a serem colhidos no exame físico. Eles deveriam fundamentar o cuidado e não repetir informações que outros profissionais utilizam. Quais são as decisōes de cuidado inerentes à prática de enfermagem? Qua is informaçōes sāo úteis c imprescindíveis para a determinação do cuidado? As técnicas propedêuticas médicas utilizadas pelo enfermeiro são adequadas para os cuidados que o enfermeiro pode determinar?

O exame das características físicas do cliente deveria privilegiar o diagnóstico de enfermagem em detrimento da patologia, uma vez que existe um profissional cujo objetivo específico é a patologia.

Desta forma os dados deveriam, prioritariamentc, subsidiar os cuidados de manutenção e controle da saúde c secundariamente, os de reparação. Ainda não atingimos a capacidade de especificar concretamente as bases dos cuidados de reparação e sub-utilizamos o que já conhecemos cientificamente em relação à manutenção das condiçōes fisiológicas do modo mais harmônico possível, diminuindo os graus de risco ou complicações c interferindo no processo saúde-doença. Deste modo, ao utilizarmos informações do exame físico conforme o modelo médico, o registro da informação não especifica o objeto do cuidado em enfermagem, ou seja, muitos achados oriundos dos testes e propedêutica médicos, não se prestam às decisōes de cuidado da enfermagem especificamente. Daí as discussōes sobre profundidade e complexidade do examc físico de enfermagem, já que o cuidado autônomo do enfermeiro, exceto se houver prescrição médica, é geralmente nāo invasivo, nāo coincidindo com as condutas que o modelo de exame físico médico sugere.

\section{III - EIXOS NORTEADORES}

Avaliando os pressupostos básicos podemos deduzir que, enquanto técnica dc exame físico:

1. a enfermagem não possui especificidade, ou melhor, não possui testes c modelos de investigação próprios, centrados no cuidado;

2. existe uma forte tendência da enfermagem para, partindo da prática atual do exame físico, centrado no modelo médico, propor uma prática centrada num "modelo cuidativo da enfermagem";

3. existe uma preocupação em se tentar definir termos próprios da enfermagem, como, "foco", "fenômeno", "diagnóstico de enfermagem", "método de enfermagem", entre outros, que delineariam algumas trajetórias para o cuidado e a prática específicos;

4. se não há especificidade quanto à técnica propriamente, com relação às finalidades existem algumas que podemos considerar específicas da enfer- 
magem. Partindo daquelas que são válidas também para outros da equipe de saúde, como: levantamento de dados, identificação de problemas, determinação de cuidados, decisão de prioridades e avaliação da assistência; três parecem-nos específicas da enfermagem; "exercer assistência preventiva"; "fazer educação para saúde" e "fazer preparo para alta".

Os eixos norteadores assim colocados, são sugestivos de algumas linhas de pesquisa indicativas de especificidade para o exame físico de enfermagem.

\section{CONCLUSÃO}

$\mathrm{Na}$ atualidade, particularmente na área da saúde, tem havido incentivos para a geraçāo das chamadas Tecnologias Apropriadas ${ }^{2}$ definidas como "aquelas que contribuem para a valorização das condições de vida de uma dada populaçāo humana e que procuram integrar um dado modelo tecnológico à organização do processo de trabalho".

Adotando este conceito para a elucidação do exame físico específico do enfermeiro, acreditamos que precisamos promover alteraçöes operacionais e metodológicas que permitam criar condiçōes mais favoráveis para a contruçāo de tecnologias apropriadas para o exame físico de enfermagem.

Há necessidade de um amplo processo de geração, seleção e transferência de tecnologias mais apropriadas à enfermagem. cuidar?

O que precisamos buscar em nosso paciente/cliente para podermos dele

FRIEDLANDER, M.R. et al. Specific characteristics of physical exa mination made by the nurse. Rev.Esc. Enf. USP, v.27, n. 1, p. 95-99, apr. 1993.

The purpose of this work is focused on the physical examinations made by the nurse, identifying four basic assumption originated from the performance of this procedure. It also suggests indicative guidelines of specificity to the nursing physical examinations.

UNITERMS: Fisical examination-nursing. Nursing as a profession.

\section{REFERÊNCIAS BIBLIOGRÁFICAS}

1. FERREIRA, B. A. et al. Um enfoque de autocuidado no exame físico de enfermagem. In: CCLO DE DEBA TES SOBRE A SISTEMATIZAÇĀO DO EXAME FÍSI CO PELO ENFERMEIRO, 1, São Paulo, 1990. Anais. Sāo Paulo, Escoda Paulista de Medicina, Departamento de Enfermagem, 1990, p. 61-91.

2. GARCIA, R.M. Tecnol ogia apropriada: amiga ou inimiga oculta? Cad. EUNDAP. v. 7, n. 13, p. 66-78, 1987.

3. LAGANÁ, M.T.C. et al. A abordagem do autocuidado: do conceito de saúde para a prática profissional. In: SEMANA WANDA DE AGUIAR HORTA, 3, Sāo Paulo, 1989. Anais, Sāo Paulo, Escal a de Enfermagem da USP, 1990. p. 207-23.

4. MITCHELL, P.H. et al. Neurdogical assessment for nursing practice. Boston, Publishing Company, 1984. 